\title{
Lusioersily
}

\section{A detailed investigation on thermal behaviour of slim floor beams with web openings at elevated temperatures}

Alam, N., Nadjai, A., Vassart, O., \& Hanus, F. (2019). A detailed investigation on thermal behaviour of slim floor beams with web openings at elevated temperatures. Journal of structural Fire Engineering, 10(4), $446-467$. https://doi.org/10.1108/JSFE-11-2018-0034

Link to publication record in Ulster University Research Portal

Published in:

Journal of structural Fire Engineering

Publication Status:

Published (in print/issue): 09/12/2019

DOI:

https://doi.org/10.1108/JSFE-11-2018-0034

\section{Document Version}

Author Accepted version

\section{General rights}

Copyright for the publications made accessible via Ulster University's Research Portal is retained by the author(s) and / or other copyright owners and it is a condition of accessing these publications that users recognise and abide by the legal requirements associated with these rights.

\section{Take down policy}

The Research Portal is Ulster University's institutional repository that provides access to Ulster's research outputs. Every effort has been made to ensure that content in the Research Portal does not infringe any person's rights, or applicable UK laws. If you discover content in the Research Portal that you believe breaches copyright or violates any law, please contact pure-support@ulster.ac.uk. 


\section{Journal of Structural Fire Engin}

\section{A detailed investigation on thermal behaviour of slim floor beams with web openings at elevated temperatures}

\begin{tabular}{|r|l|}
\hline Journal: & Journal of Structural Fire Engineering \\
\hline Manuscript ID & JSFE-11-2018-0034.R2 \\
\hline Manuscript Type: & Research Paper \\
\hline Keywords: & $\begin{array}{l}\text { Slim floor beams, Web openings, Thermal response, Fire tests, Finite } \\
\text { element modelling }\end{array}$ \\
\hline
\end{tabular}

\section{SCHOLARONE \\ Manuscripts}




\begin{abstract}
Steel beams with web openings are widely used in construction to reduce the weight of steelwork, especially in structures comprising of traditional composite beams with down-stand steel sections. The composite action in these beams is achieved either through the concrete dowels or through concrete plugs. Though these web openings offer several benefits in slim floor beams, they induce the material discontinuity in the steel web which may affect their shear capacity and/or thermal behaviour. During the pouring of concrete, the steel in these web openings is replaced by the concrete with a low thermal conductivity. This research presents findings from experimental and analytical investigations conducted to study the thermal behaviour of slim floor beams with web openings in fire. For this purpose, an experimental investigation was conducted which shows that the presence of web openings has a considerable influence on temperature development across the steel section as well as along the span of these beams. Temperatures on the web below the openings are found to be higher compared to those recorded on the adjacent solid steel web. It is also observed that temperatures on the steel web above the openings are lesser than those on the adjacent solid steel web. Parametric studies conducted using the verified analytical modelling methods show that different opening spacings, sizes and shapes have a variable impact on the thermal behaviour of slim floor beams in fire. Closely spaced and larger opening sizes were found to have a more severe influence on their thermal behaviour in fire compared to widely spaced and smaller openings. It was also found that the behaviour of these beams is influenced by the shape of the openings with rectangular openings resulting in more severe thermal distributions compared to circular openings. The findings of this research will help with the design of slim floor beams with web openings and will help with better selection of opening spacings, sizes and shapes. Such designs will ensure the stability of slim floor beams in fire.
\end{abstract}

Keywords: Slim floor beams, web openings, thermal response, fire tests, finite element modelling

\title{
1. Introduction
}

Although the use of composite beams offers longer floor spans, these beams in most cases are deeper in comparison with reinforced concrete beams. This increase in depth is a major disadvantage, especially in tall buildings. The use of slim floor beams in high-rise buildings is advantageous due to their shallower depths resulting from the partial encasement of steel section within the floor [1]. The partial encasement protects the steel sections from direct exposure to heat and fire and improves their fire resistance. The concrete encasement also contributes towards the stiffness of the slim floor beams enhancing their bending resistance by reducing deflections and vibrations in service conditions.

The use of the slim floor beams aids in reducing the construction cost as they consume lesser building materials. The combination of these beams with the metal decking reduces the construction time and eliminates additional requirements of formwork and scaffolding [2] [3]. Slim floor beams also help in assimilating the services within the floor depth through the web openings. Though the web openings offer numerous advantages, they also reduce the vertical shear resistance of these beams. Previous 
experimental and analytical investigations have shown that the concrete between the flanges of the steel section in these beams contributes towards their shear capacity compensating for the loss of the steel web. In some cases, the encased concrete increases their shear capacity significantly, twice as that offered by the bare steel beam section [4] [5]. Further, experimental investigations have also been conducted to study the longitudinal shear resistance offered by these beams in terms of the composite action resulting from the concrete dowels or concrete plugs. These investigations have shown that the presence of the concrete dowels and plugs improve the longitudinal shear stress transfer mechanism in these beams [6]. Though several investigations are available in literature which address their behaviour at ambient temperatures [4] [5] [6], their response at elevated temperatures needs to be investigated and addressed.

\subsection{Aims and objectives}

The work presented herein is an experimental and analytical investigation conducted to study the influence of the web openings on thermal response of slim floor beams in fire. This investigation addresses any influences of material discontinuities and the resulting influences on their thermal behaviour in fire. Data acquired from this test is one of its kind and will help to understand the behaviour of these beam types at elevated temperatures. Analytical investigations on the spacings, sizes and shapes of the web openings will highlight the influence of these parameters on the fire behaviour of slim floor beams and will help with better designs and improved solutions for future use.

\subsection{The scope of research}

The scope of this study is limited to investigations on thermal behaviour only. During this research program, no investigations are conducted to analyse the influence of the web openings on the structural response of slim floor beams in fire.

\section{Experimental programme}

\subsection{Test specimen and heating conditions}

The fire test was conducted on a slim floor beam assembly to analyse any influence of the presence of web openings on the thermal behaviour in fire. As mentioned before, the scope of this study is limited to investigations on thermal behaviour only, hence, no external loads were applied on the specimen during the test. The tested slim floor beam assembly was $1000 \mathrm{~mm}$ wide and $2000 \mathrm{~mm}$ long, corresponding to the size of the furnace which is $2000 \mathrm{~mm}$ x $2000 \mathrm{~mm}$ in the plan. The slim floor beam consisted of a steel section, HEA-220 and a steel plate $400 \mathrm{~mm}$ wide and $15 \mathrm{~mm}$ thick made from grade S355 steel. This steel plate was welded to the bottom flange of the steel beam along its length. The overall depth of steel section was $225 \mathrm{~mm}$ including the welded plate as shown in Figure 1 (c). The composite floor consisted of a steel decking and normal weight concrete with a target strength of $30 \mathrm{~N} / \mathrm{mm}^{2}$ at 28 days. The steel decking used for the floor construction is MD-50, a profiled and galvanised steel floor decking used for the construction of composite floor slabs. The overall depth of the test assembly was $280 \mathrm{~mm}$ including a $55 \mathrm{~mm}$ layer of concrete above the top flange and the $15 \mathrm{~mm}$ thick welded steel plate as shown in Figure 1. Concrete above the top flange was reinforced using A-142 steel mesh with flying ends and with minimum laps of $400 \mathrm{~mm}$. This reinforcing mesh is positioned using $15 \mathrm{~mm}$ deep spacers to maintain its position above the top flange. The sides of the slim floor beam assembly consisted of steel sheets which served as a permanent formwork during the construction as shown in Figure 1 (b).

The steel section of the slim floor beam was fabricated with $100 \mathrm{~mm}$ diameter web openings with centre to centre spacings of $200 \mathrm{~mm}$ throughout its length. In total, 10 openings were fabricated in the web in such a way that their centres coincided with the centreline of the web, $94 \mathrm{~mm}$ from the top and the bottom flange. During the fabrication of the web openings, a solid steel web with a minimum width of $100 \mathrm{~mm}$ was produced between the edges of the openings as shown in Figure 1 (a). The first 
openings at both ends of the steel section were positioned at $100 \mathrm{~mm}$ centres from the beam edges which produced a solid steel web of $50 \mathrm{~mm}$ at beam ends. The minimum depth of the solid steel web above and below the edge of openings was $44 \mathrm{~mm}$.

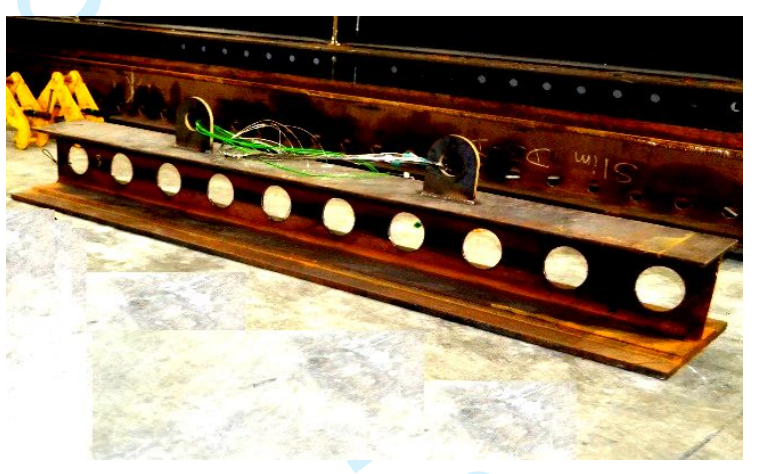

(a)
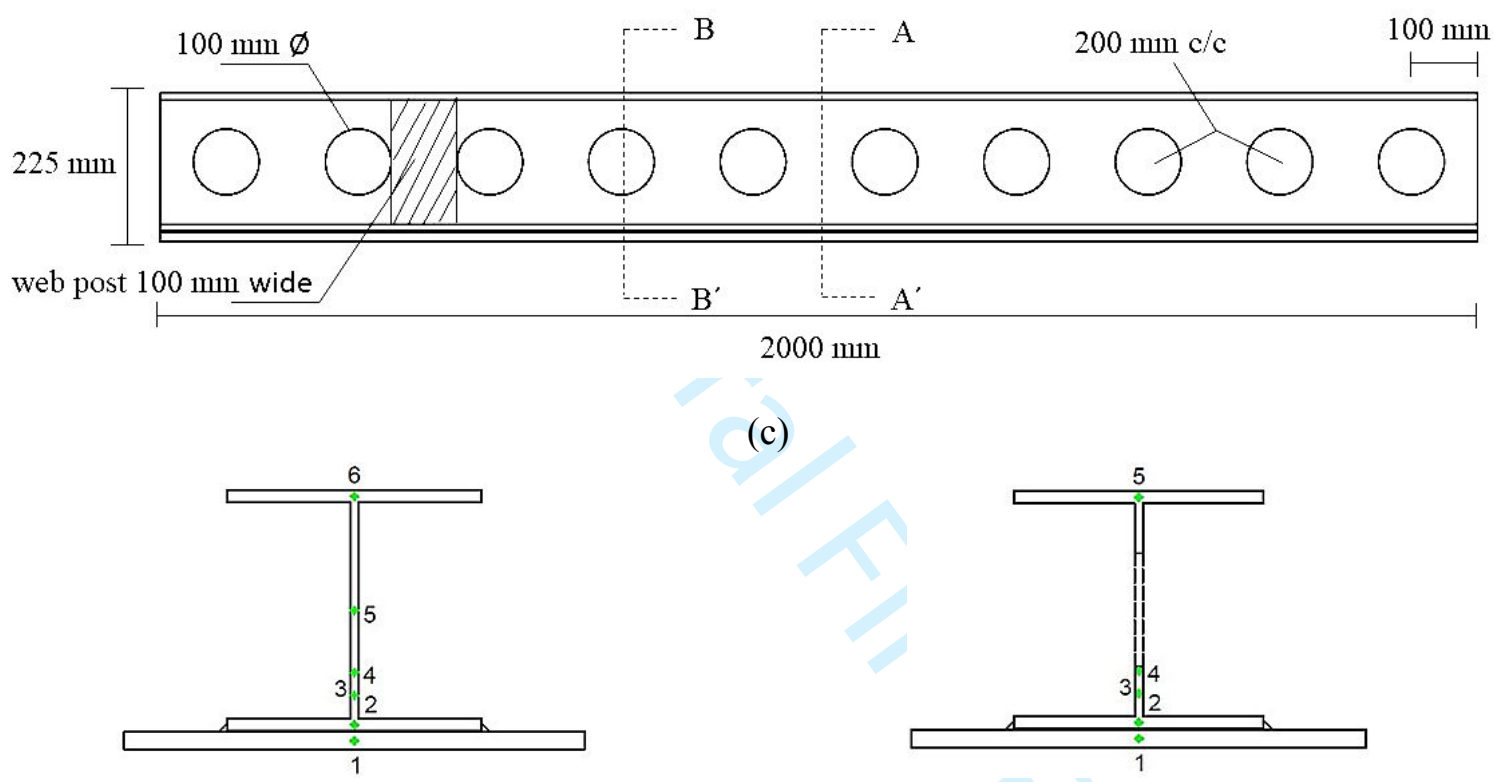

(d) (c)

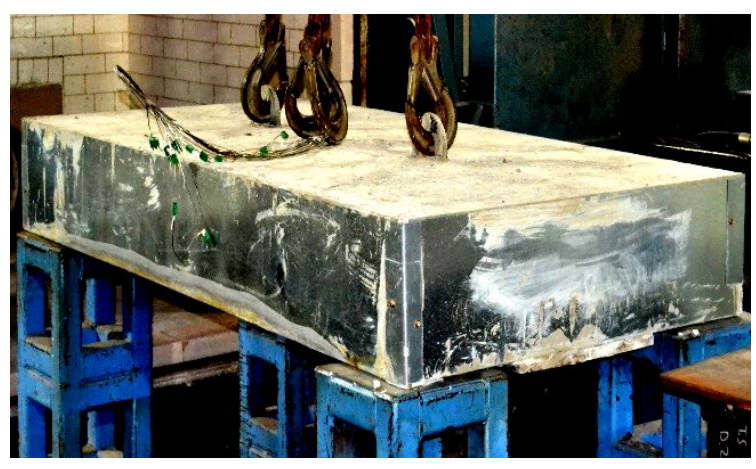

(b)

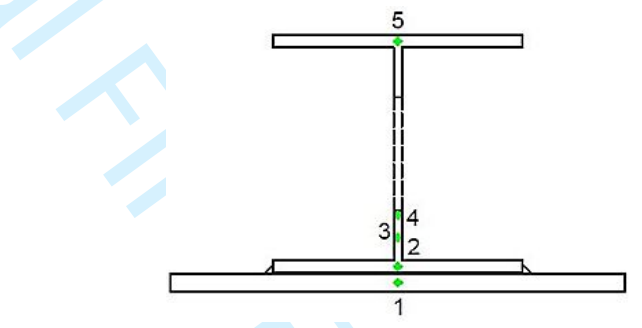

(e)

Figure 1: Details of the test assembly, (a) Steel beam with web opening; (b) test specimen with composite slab; (c) Side Elevation of the steel beam; (d) Section at AA'; (e) Section at BB'

During the fire test, only thermal data was recorded while no arrangements were made to document any vertical or horizontal deformations. Temperatures within the furnace and on the slim floor beam assembly were recorded using type K-310 thermocouples. The furnace temperatures were monitored via five thermocouples to ensure the heating conditions were in accordance with the standard fire, ISO-834. The temperatures on the slim floor beam assembly were monitored through thermocouples positioned on the steel beam at two locations along its span, section $\mathrm{AA}^{\prime}$ and section $\mathrm{BB}^{\prime}$ shown in Figure 1 (c). These sections are positioned along the centreline of the openings and in the middle of the solid steel web respectively. The temperatures at section $\mathrm{AA}^{\prime}$ were monitored using six thermocouples, one each positioned on the middle of the welded steel plate, bottom flange and the top flange while the remaining three were positioned on the steel web. Two of the thermocouples on the steel web were positioned at $20 \mathrm{~mm}$ and $40 \mathrm{~mm}$ from the inner edge of the bottom flange while the third one was positioned in the middle of the steel web as shown in Figure 1 (d). The temperatures at the web opening were monitored at section $\mathrm{BB}^{\prime}$ using five thermocouples. Three of these 
thermocouples were positioned in the middle of flanges and welded steel plate. The thermocouples on the web were positioned at $20 \mathrm{~mm}$ and $40 \mathrm{~mm}$ from the inner edge of the bottom flange as shown in Figure 1 (e). Thermocouple positioning at section $\mathrm{AA}^{\prime}$ and $\mathrm{BB}^{\prime}$ was kept similar except for the one on the middle of the steel web at section $\mathrm{AA}^{\prime}$. Such an arrangement of thermocouples was valuable in investigating the influence of the web openings on the thermal behaviour of slim floor beams as they represent the parts of the steel beam at the openings and as well as at the solid steel web.

\subsection{Test procedure and results}

The fire test on the slim floor beam assembly with web openings was conducted at Fire Safety Engineering Research and Technology (FireSERT), Ulster University on the 18th of January 2018. The test was conducted using a gas-fired furnace which lasted 90 minutes. The test assembly was placed on top of the furnace which covered the central $1000 \mathrm{~mm}$ furnace width while the remaining part of the furnace top was covered using reinforced concrete slabs. The interface between the test assembly and the concrete slabs was filled using ceramic fibre blanket to control the heat and smoke and to allow any vertical deformations of the test beam resulting at higher temperatures. In addition, any openings in the furnace were filled using the fibre blanket to control smoke and heat. As the test was conducted to investigate only the thermal behaviour of slim floor beams, no special support conditions were provided at the ends and the beam assembly rested directly on top of the frame built over the furnace walls. To accommodate any expansion resulting at higher temperatures, no restraints were applied to the ends of the test assembly. All thermocouples were connected to the data logging system where the temperatures were recorded for the whole duration of the fire test. Once the beam assembly was ready for testing, it was heated in accordance with the standard fire curve, ISO-834 [7]. The heating of the test assembly continued for a period of 90 minutes during which thermal data was recorded. After 90 minutes of standard fire exposure, the test was stopped, and the data acquisition was discontinued.

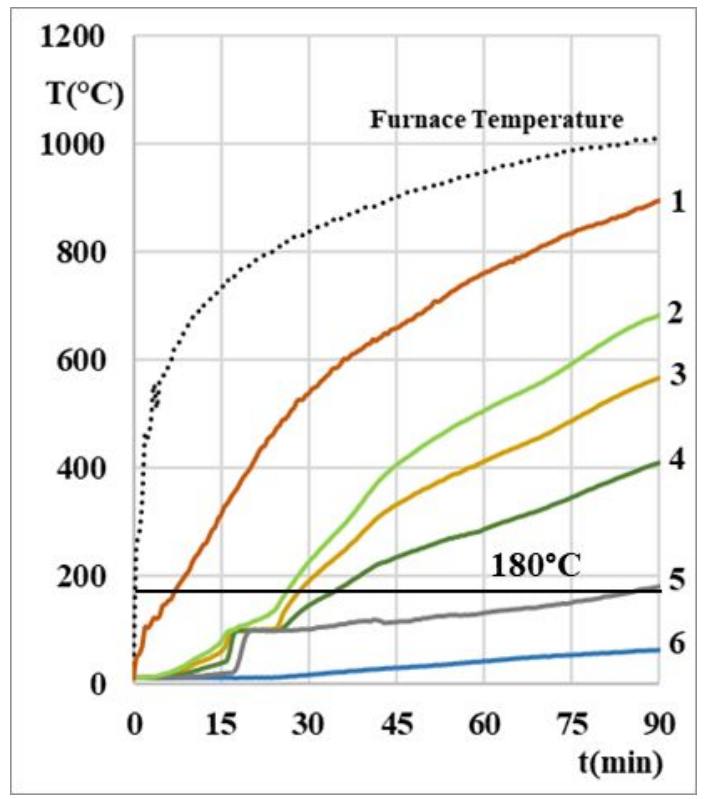

(a)

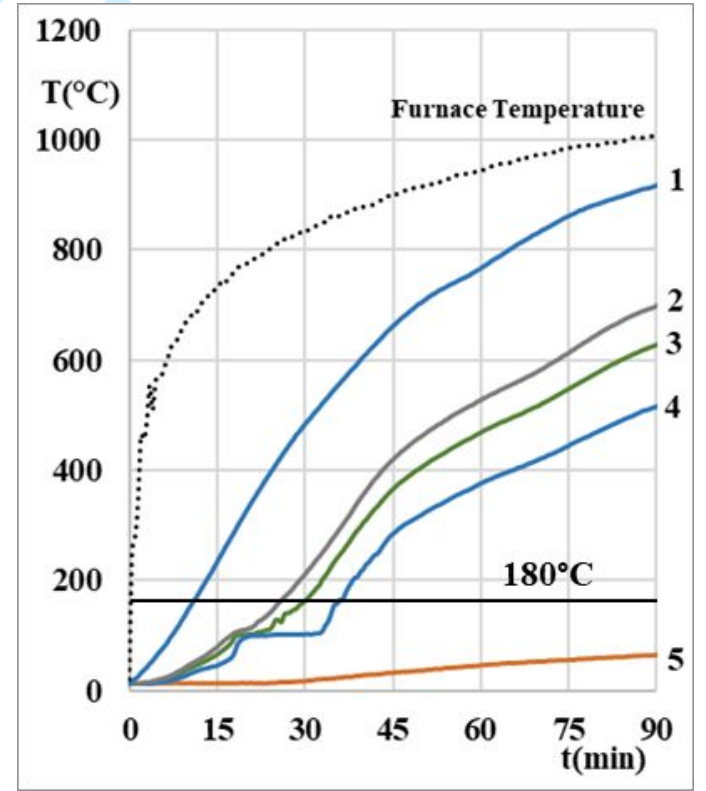

(b) 


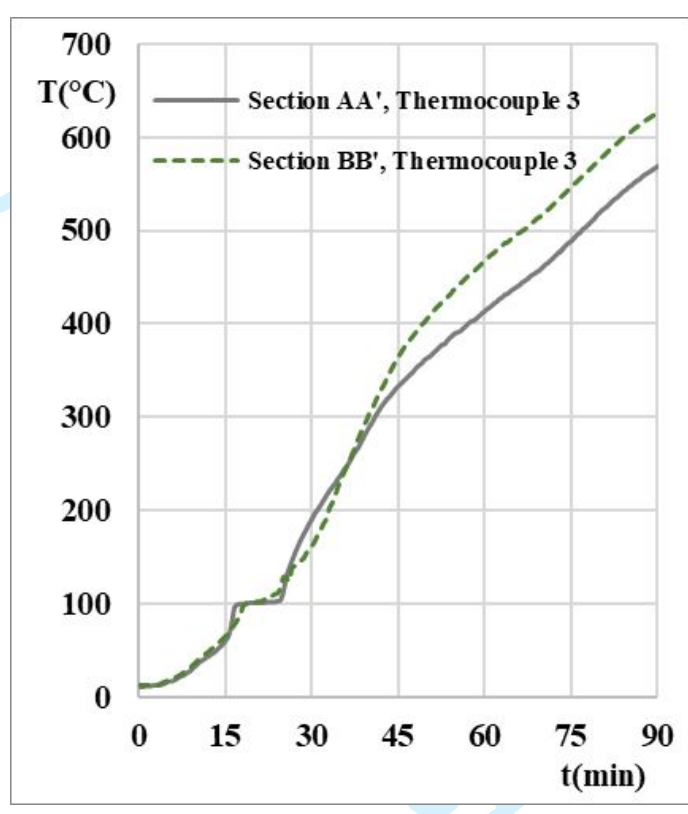

(c)

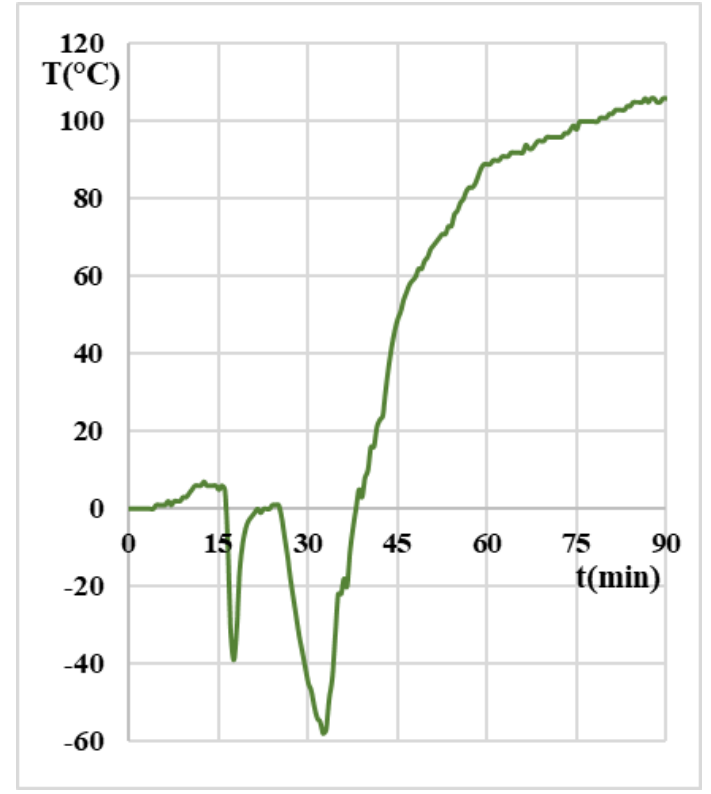

(d)

Figure 2: Figure showing the test data, (a) Recorded temperatures at Section AA'; (b) Recorded temperatures at Section BB'; (c) Temperatures at section $A A^{\prime}$ and $B B^{\prime}$ for thermocouple position 3; (d) Temperatures difference for thermocouple position 3 at section $A A^{\prime}$ and $B B^{\prime}$

Data acquired during the fire test in terms of the temperatures recorded at thermocouple positions at section $\mathrm{AA}^{\prime}$ and section $\mathrm{BB}^{\prime}$ are presented in Figure 2 (a) and Figure 2 (b) respectively. The numbers corresponding to temperatures in Figure 2 represent the thermocouple positions shown earlier in Figure 1 (d) and Figure 1 (e). Similar to the results obtained from the previous investigations on the slim floor beams [8] [9] [10], a high thermal gradient across the beam section was observed with the exposed lower parts being at higher temperatures in comparison to the unexposed upper parts. It is also observed that there is a higher temperature difference between the welded steel plate and the bottom flange of the steel beam as shown in Figure 2 (a) and Figure 2 (b). These temperature differences are more than $250^{\circ} \mathrm{C}$ after 25 minutes of fire exposure and remain high throughout the duration of the fire test similar to the results in a previous investigation by the authors [11]. The recorded temperatures on the top flange remain below $180^{\circ} \mathrm{C}$ throughout the duration of the fire test, hence the insulation criteria are satisfied. These criteria have been defined in BS 476 part 20 section 10.4 [18] It states that the temperature on the unexposed surface should not exceed $140^{\circ} \mathrm{C}$ on average and $180^{\circ} \mathrm{C}$ at any position. As the fire test was conducted to investigate the influence of the web openings on thermal behaviour of slim floor beams in fire, the temperatures recorded at thermocouple position 3 at section $\mathrm{AA}^{\prime}$ and $\mathrm{BB}^{\prime}$ are presented in Figure 2 (c). It is seen that the temperatures recorded on the steel web under the opening are higher compared to those recorded on the solid steel web at same thermocouple positions. These temperature differences are presented in Figure 2 (d) which shows a temperature difference of $90^{\circ} \mathrm{C}$ and $107^{\circ} \mathrm{C}$ after a fire exposure of 60 minutes and 90 minutes respectively. The resulting temperature difference is due to the discontinuity of the steel in the web. During the pouring of concrete, the steel in the web opening is replaced by the concrete which has a lower thermal conductivity. This concrete restricts the efficient flow of heat across the beam section when exposed to fire. As a result, the temperatures on the web under the openings are higher in comparison to those on the adjacent solid steel web. The recorded test data shows that the presence of the web openings in slim floor beams has a considerable influence on their thermal behaviour in fire. It is interesting to note that a phase delay exists for around 10 minutes once the temperature at thermocouple position 3 reaches $100^{\circ} \mathrm{C}$. This is due to the migration of moisture which consumes the heat. 


\section{$3 \quad$ Analytical modelling}

\subsection{Methodology}

Finite element modelling for the test assembly was performed using ABAQUS [12]. Though several analytical investigations are available on the behaviour of shallow floor systems in fire, these previous studies address the slim floor beams with no web openings [8] [13]. The current study is the first of the analytical investigations addressing the behaviour of slim floor beams with web openings at elevated temperatures. The proposed analytical method is first validated by replicating the data acquired during the fire test. To make the analysis economical in terms of time, a quarter of the test assembly is modelled during the validation process. The beam assembly is heated using the recorded furnace temperatures during the analytical modelling. The boundary conditions of the beam assembly are kept similar to those used during the test. Non-linear material properties, including the thermal conductivity, specific heat, and the density are taken from the Eurocodes, EN 1994-1-2 [14]. The steel and concrete parts of the assembly are modelled using 8-node hexahedral solid linear heat transfer elements (DC3D8), commonly used for such analytical investigations. Heat transfer through the surfaces of the test assembly is modelled via convection and radiation. The convection coefficients for exposed and unexposed surfaces are taken as $25 \mathrm{~W} / \mathrm{m}^{2} \mathrm{~K}$ and $9 \mathrm{~W} / \mathrm{m}^{2} \mathrm{~K}$ respectively following the Eurocode (EN 1992-1-2) recommendations [15]. Any heat transfer through radiation from the unexposed surfaces is ignored while the same for the exposed surfaces and for the cavity between the welded plate and bottom flange, is modelled using an emissivity of 0.7 following the recommendation of the Eurocodes (EN 1993-1-2 and EN 1991-1-2), [16] [17]. Perfect thermal contact is modelled between the steel and the concrete which allows efficient and full heat transfer between these materials. Similar thermal contacts for these material types have previously been modelled during analytical investigations conducted on shallow floor systems [8] [13].

\subsection{Results}

Results obtained from the analytical modelling of the slim floor beam assembly are presented in Figure 3. The thermal contours in Figure 3 show the influence of web openings on the heat transfer across the section as well as along the span of the slim floor beam. The thermal contours for the beam are presented at the beginning of the analysis before fire exposure and at time intervals of 15, 30, 45 . 60 and 90 minutes of fire exposure respectively. Similar to the fire test, temperatures predicted on the web below the opening are higher compared to those predicted on the adjacent thermocouple positions on the solid steel web. The thermal contours show that the temperatures on the web above the openings are lesser than those predicted on the adjacent solid steel web at the same positions. The thermal gradient in the analytical model is significant for the slim floor beam throughout the during of the fire exposure because of the concrete encasement. It is seen that with the increase in the fire exposure time, the temperatures predicted on the solid steel web are higher compared to those predicted in the adjacent concrete in the web opening. Similarly, the thermal contours show that the predicted temperatures on the part of the web above the web openings are much lesser than those predicted on the adjacent solid steel web. The maximum temperatures are predicted on the welded steel plate where the recorded temperatures are $973.5^{\circ} \mathrm{C}$ after 90 minutes of heating. The temperature difference between the welded steel plate and the bottom flange was also predicted to be high. The top flange of the slim floor beam is much cooler than the bottom part of steel beam and the predicted temperatures after 90 minutes of fire exposure remain below $100^{\circ} \mathrm{C}$ for this part. 

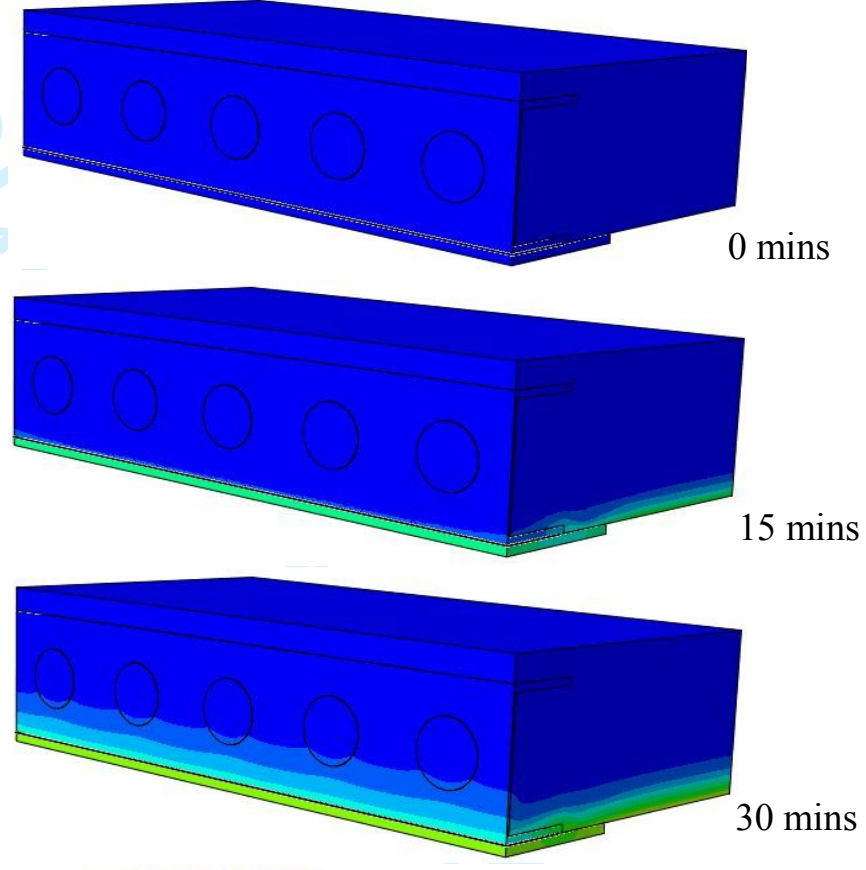

NT11
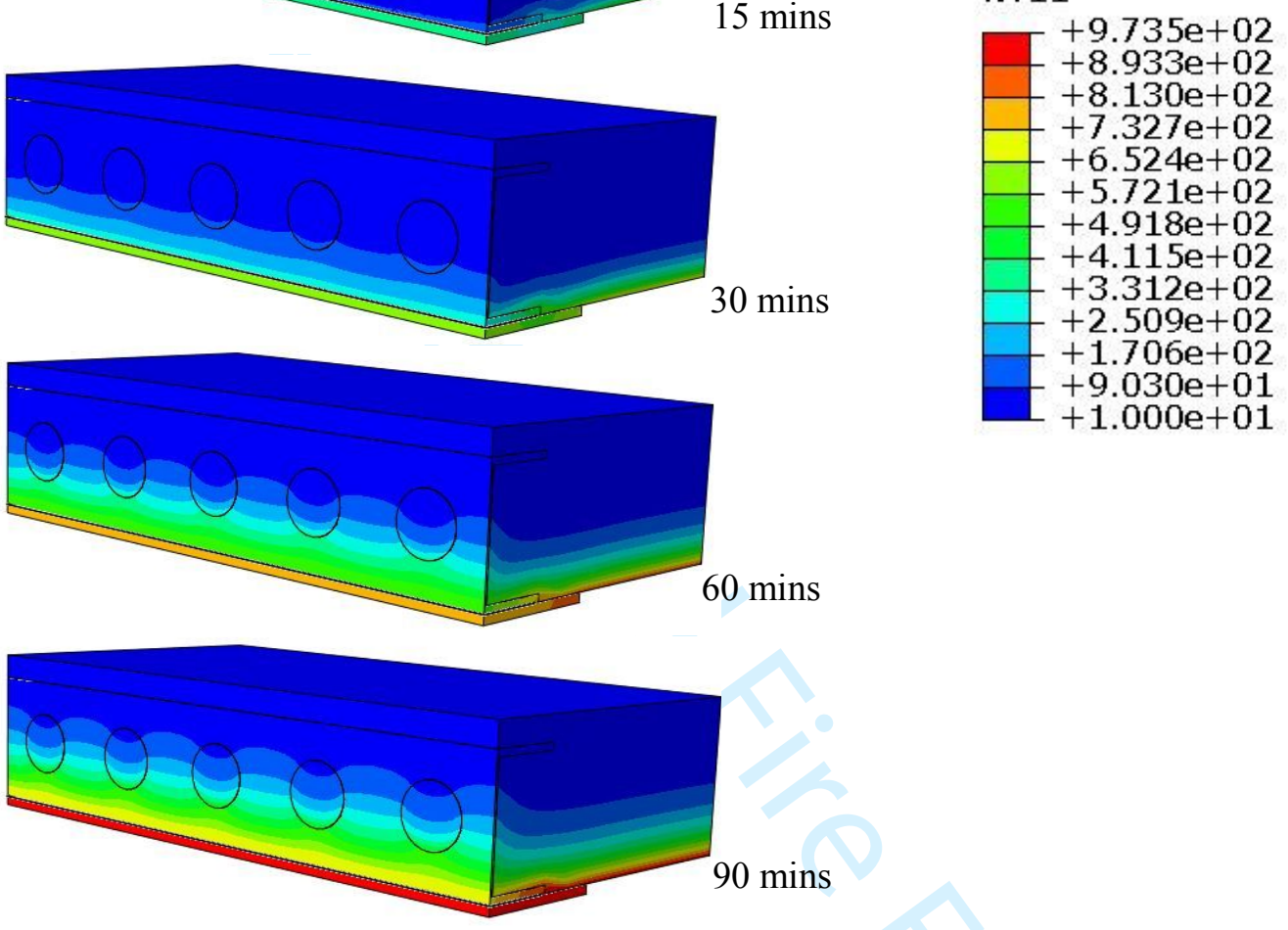

Figure 3: Analytical results showing thermal contours at different time intervals of ire exposure

Thermal predictions obtained from the analytical modelling are presented and compared with the recorded test data for different thermocouple positions in Figure 4. The numbers corresponding to the thermal data in Figure 4 are the thermocouple positions which represent their positions on the steel beam at section $\mathrm{AA}^{\prime}$ and section $\mathrm{BB}^{\prime}$ as shown earlier in in Figure 1 (d) and Figure 1 (e). As seen in Figure 4 (a), the thermal predictions from the analysis are in close agreement with the recorded test

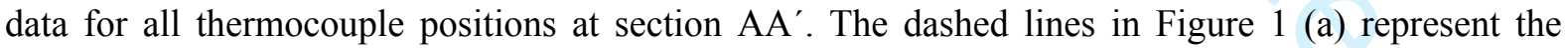
thermal predictions from the analytical modelling while the solid lines represent the recorded test data at the same location. Similarly, the thermal predictions obtained for all five thermocouple positions at section $\mathrm{BB}^{\prime}$ are also in very good agreement with the test data as shown in Figure 4 (b). 


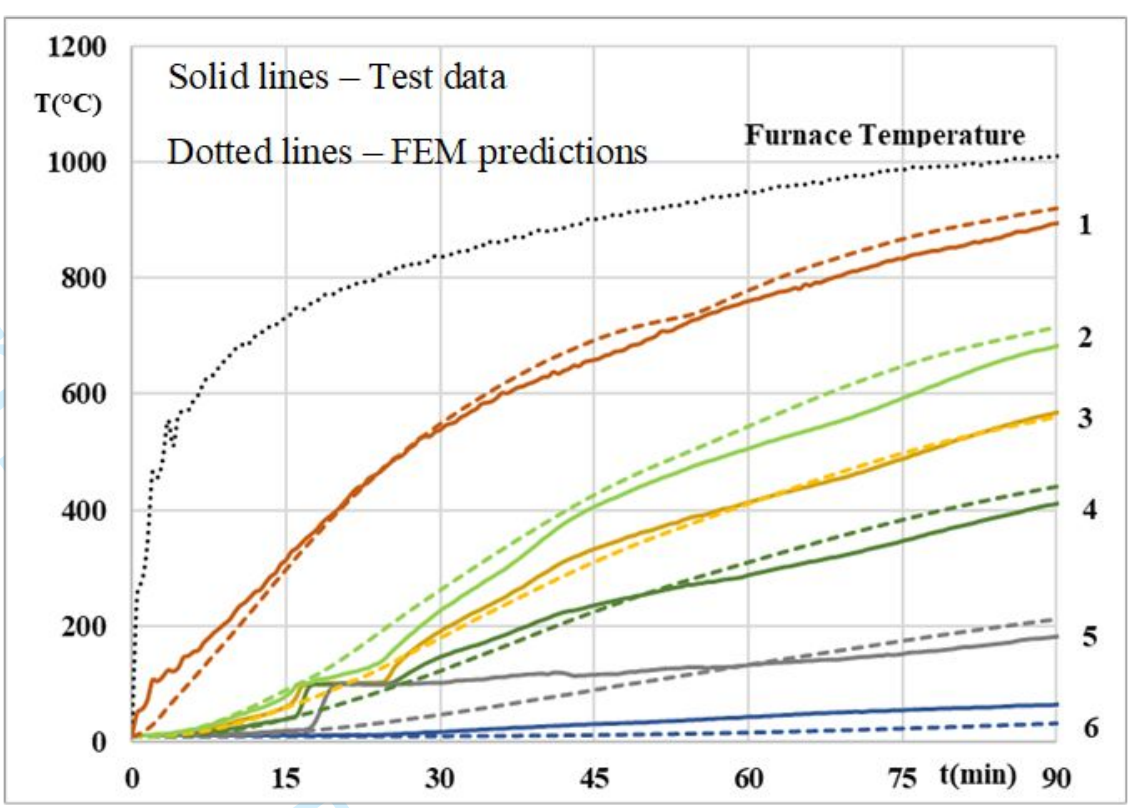

(a)

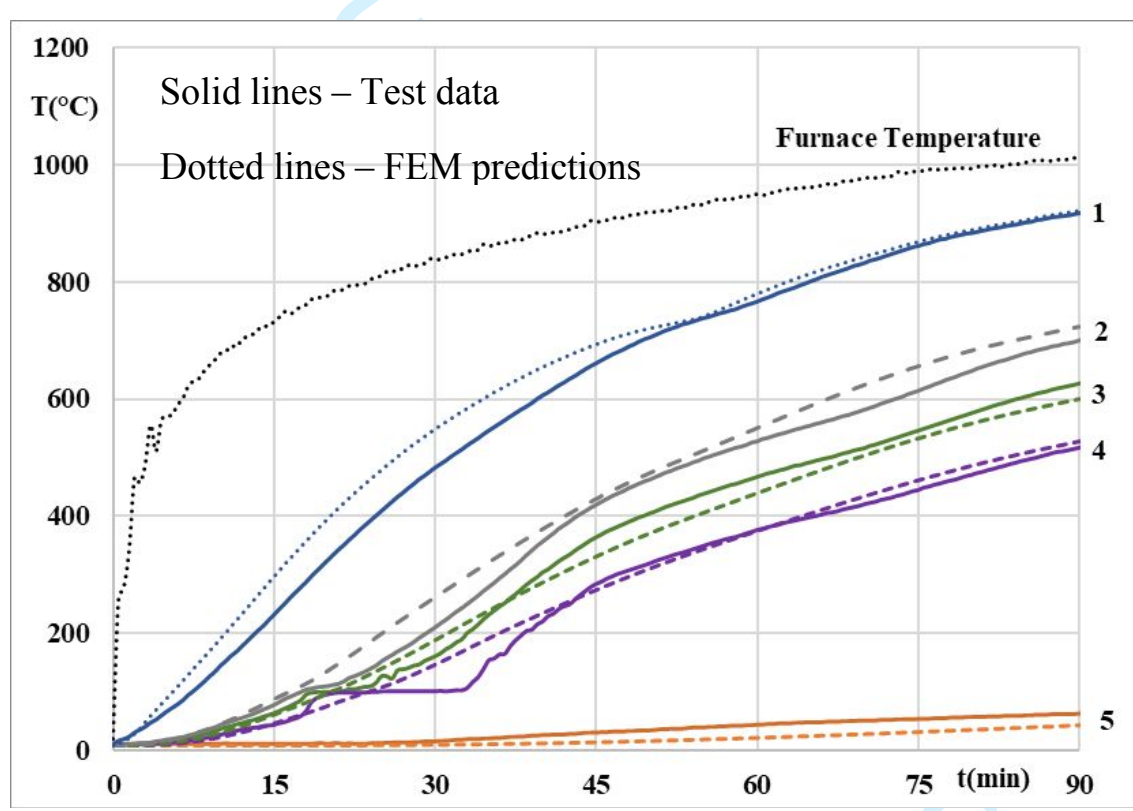

(b)

Figure 4: Comparison of test data and analytical modelling predictions, (a) Section AA'; (b) Section BB'

It is seen that the thermal predictions from the analytical modelling are in very good agreement with the test data for thermocouple positions at the solid steel web as well as for the part of the slim floor beam section where the steel web is discontinuous due to the presence of the openings. These results show that the analytical modelling method used in this study can predict the thermal response of slim floor beams with web openings with good accuracy. Hence, the analytical method can be used to conduct sensitivity studies to investigate the influence of different parameters related to web openings on the thermal behaviour of slim floor beams at elevated temperatures. 


\section{Sensitivity studies}

A sensitivity analysis was conducted to analyse the influence of the spacing, size and shape of the web openings on thermal behaviour of slim floor beams at elevated temperatures. During this part of the research, the verified analytical modelling method detailed in section 3 was used and one-fourth of the test assembly was modelled. The ambient temperature during the analytical investigations was set at $20^{\circ} \mathrm{C}$ in all cases. The influence of different opening spacings, sizes and shapes is investigated in terms of predicted temperatures on the steel web below and above the openings and those predicted on the solid steel web at similar thermocouple positions. Further, the predicted temperatures on the parts of the steel web influenced by the design modifications resulting from the variations in the spacings, sizes and shapes of the openings are also provided.

\subsection{Sensitivity studies on centre to centre spacing of openings}

To investigate the influence of the centre to centre spacings of the openings, four slim floor beams with variable opening spacings were modelled and analysed. The shape and size of the openings and their position along the vertical axis of the beam was kept same in all cases. The circular openings were $100 \mathrm{~mm}$ in diameter and were positioned at $44 \mathrm{~mm}$ from the inner edges of the top and the bottom flanges. Four cases of the opening spacings were investigated where the centre to centre spacings were kept $150 \mathrm{~mm}, 200 \mathrm{~mm}, 300 \mathrm{~mm}$ and $600 \mathrm{~mm}$ as shown in Figure 5. The variations in the opening spacings results in different widths of the solid steel web between the openings. For the slim floor beam assembly with $150 \mathrm{~mm}$ opening spacings, the minimum width of the solid web was $50 \mathrm{~mm}$ while for the ones with $200 \mathrm{~mm}, 300 \mathrm{~mm}$ and $600 \mathrm{~mm}$ opening spacings, the minimum width of the solid steel web was $100 \mathrm{~mm}, 200 \mathrm{~mm}$ and $500 \mathrm{~mm}$ respectively. These variations in the geometry of the slim floor beams are presented in Figure 5. With the exception of the variations in the opening spacings, the slim floor beam used during this part of the study is similar to the slim floor beam used during the experimental investigation and the one used during the analytical modelling presented earlier in section 3 .

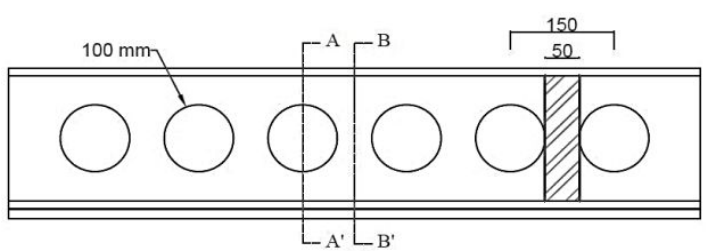

(a)

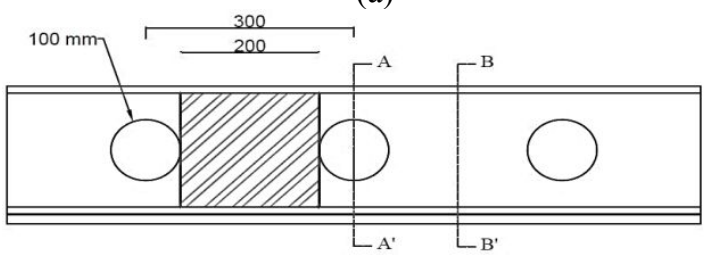

(c)

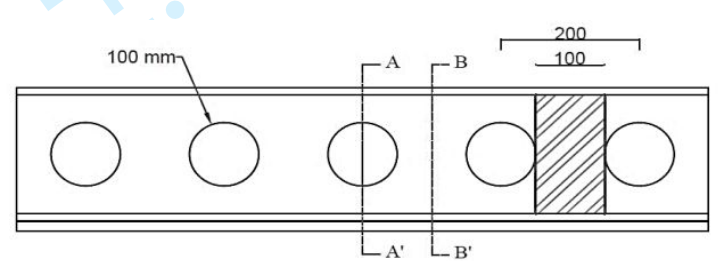

(b)

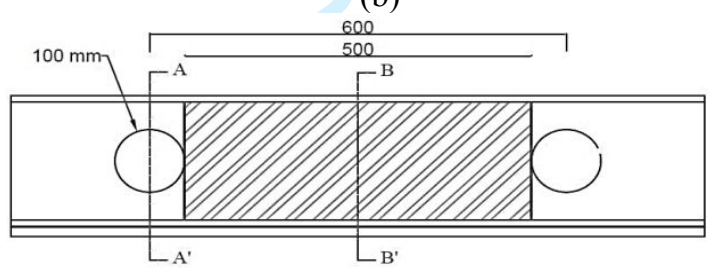

(d)

Figure 5: Slim floor beam assemblies with $100 \mathrm{~mm}$ diameter openings and different spacings, (a) at $150 \mathrm{~mm}$ centres; (b) at $200 \mathrm{~mm}$ centres; (c) at $300 \mathrm{~mm}$ centres; (d) at $600 \mathrm{~mm}$ centres

\subsection{Sensitivity studies on the size of openings}

The size of the web openings for slim floor beams has been found to vary from one beam to another depending upon the design and utility requirements. No restriction on the minimum size of the web openings is available in literature while the maximum allowable size of these openings is recommended not to exceed $70 \%$ of the web depth [6]. Being mindful of the various possibilities for 
sizes of the web openings, a sensitivity study was conducted to investigate the influence of $50 \mathrm{~mm}, 70$ $\mathrm{mm}, 100 \mathrm{~mm}$ and $130 \mathrm{~mm}$ web opening sizes on thermal response of slim floor beams in fire. The minimum width of the solid steel web between the openings was kept same and equal to $100 \mathrm{~mm}$ in all four cases as shown in Figure 6. The maximum size of the openings selected during this study, 130 $\mathrm{mm}$, represents the openings with approximately $70 \%$ of the web depth. The investigated slim floor beam assembly was again similar to the test specimen and the beam assembly used for analytical investigations described earlier in section 3 .

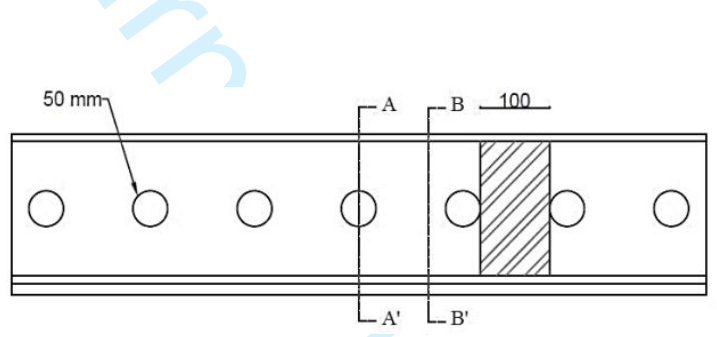

(a)

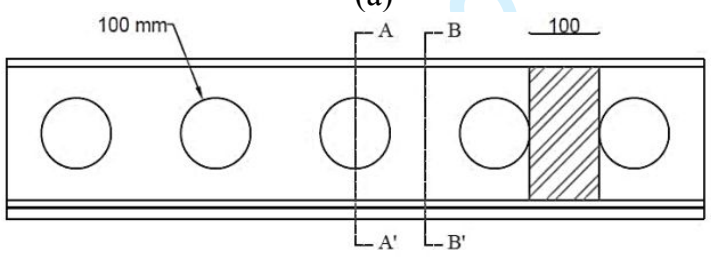

(c)

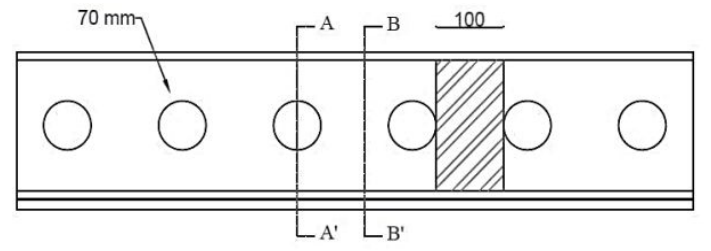

(b)

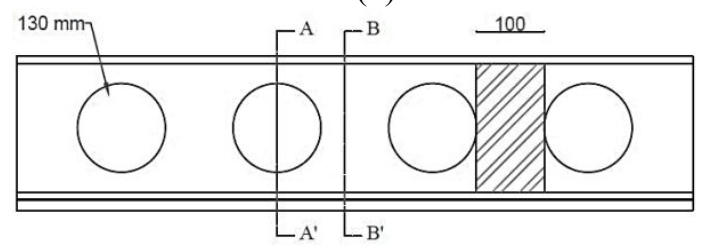

(d)

Figure 6: Slim floor beams with $100 \mathrm{~mm}$ solid steel width and different opening sizes, (a) $50 \mathrm{~mm}$ diameter openings; (b) $70 \mathrm{~mm}$ diameter openings; (c) $100 \mathrm{~mm}$ diameter openings; (d) $130 \mathrm{~mm}$ diameter openings

\subsection{Sensitivity studies on the shape of openings}

During the experimental programme and during the analytical investigations conducted in the above sections, only circular shaped web openings with different sizes and spacings have been investigated. Though the use of circular web openings is common, various other shapes of web openings may also be encountered during construction work. Among other opening shapes, squared openings, elongated openings and rectangular openings are often used in the construction. In this part of the study, investigations are conducted on slim floor beam assemblies with circular, elongated, squared and rectangular web openings such that the minimum width of the solid steel web as well as the depth of the steel web above and below the openings is kept constant in all cases. The investigated slim floor beam cases with different opening shapes are shown in Figure 7 . The circular openings investigated are $100 \mathrm{~mm}$ in diameter while the square openings are $100 \mathrm{~mm}$ in each direction. The elongated openings have a maximum length of $300 \mathrm{~mm}$ including a semi-circle of $100 \mathrm{~mm}$ diameter at each end. Similar to the elongated opening, the rectangular openings are $300 \mathrm{~mm}$ long. The depth of the elongated and the rectangular openings is $100 \mathrm{~mm}$, similar to the depth of the square and circular openings. The details of the investigated cases are presented in Figure 7 which shows the minimum width of the solid steel web between the openings in all cases was $100 \mathrm{~mm}$. The depth of the steel web above and below the openings was also equal for all cases with the edge of the openings being at 44 $\mathrm{mm}$ from the inner edges of the top and the bottom flanges. 


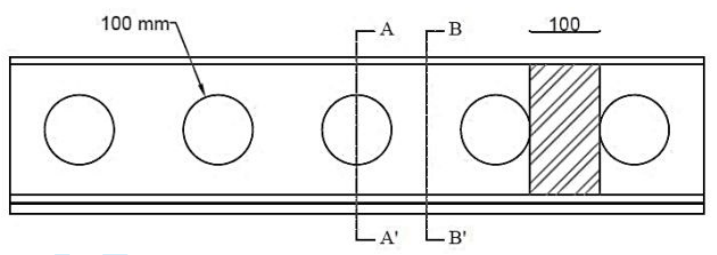

(a)

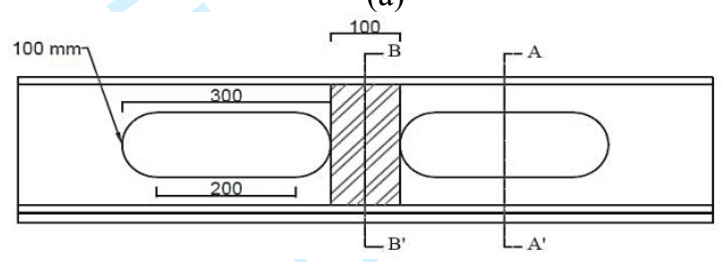

(c)

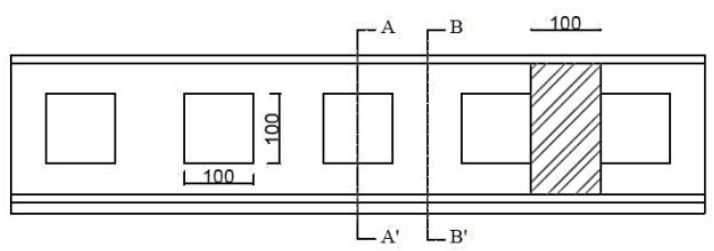

(b)

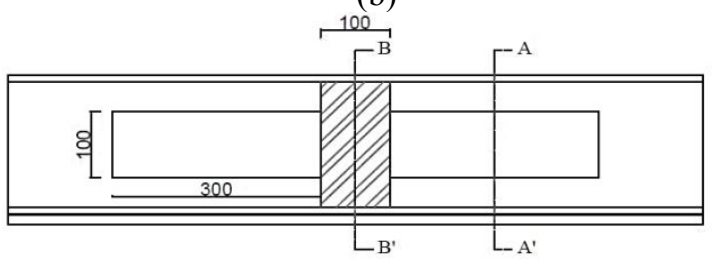

(d)

Figure 7: Slim floor beam assemblies with $100 \mathrm{~mm}$ solid steel width and with different opening shapes, (a) 100 mm diameter circular openings; (b) 100 mm square openings; (c) $300 \mathrm{~mm}$ elongated openings; (d) $300 \mathrm{~mm}$ rectangular openings

\section{$5 \quad$ Results from sensitivity studies}

Results obtained from the sensitivity analysis are presented here for different slim floor beam cases. As mentioned in the proceeding sections, sensitivity investigations were conducted to analyse the influence of the opening spacings, sizes and shapes on the thermal behaviour of slim floor beams. The results presented herein highlight the influences resulting from these design variations. The results obtained for each part of the sensitivity investigation are presented in the following sections;

\subsection{Sensitivity studies on centre to centre spacing of openings}

The influence of the variation in the centre to centre spacing of the openings on the thermal behaviour of slim floor beams are presented in terms of temperatures predicted on the steel web. The results from the analysis are presented in terms of the temperatures predicted for thermocouple positions above and below the centreline of the web openings and those predicted on the adjacent solid steel web at similar thermocouple positions. Since the size of the web openings was kept $100 \mathrm{~mm}$ in diameter in all cases, hence the centre to centre spacing between these openings changed the width of the solid steel web from one case to another. The thermal contours obtained from the analytical modelling after a period of 120 minutes of standard fire exposure for all four cases are presented in Figure 8. It is seen that the thermal contours on the slim floor beam in each case are different. This shows that the variations in the opening spacings has an influence on the thermal behaviour of slim floor beams in fire. The fire test was conducted for 90 minutes, hence, the model verification presented earlier is presented 90 minutes. On the other hand, the sensitivity study was conduced for an additional 30 minutes, the results for the sensitivity study are presend for an extended duration of 120 minutes. 


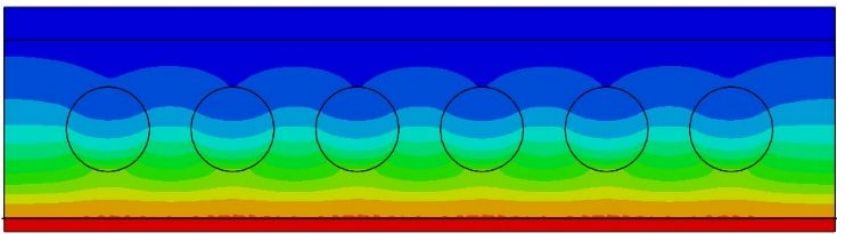

(a)

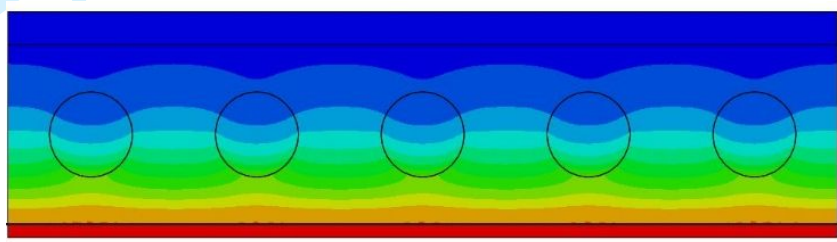

(b)

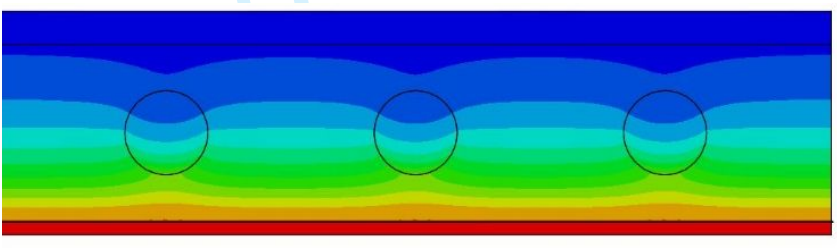

(c)

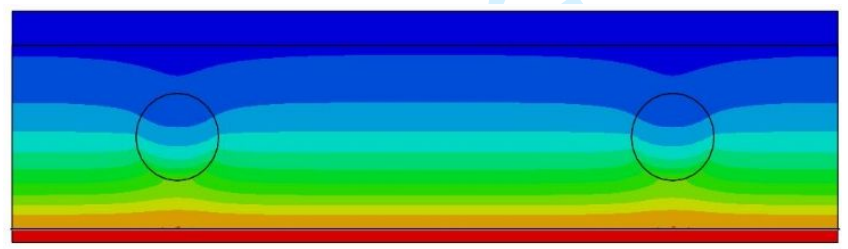

(d)

Figure 8: Analytical results showing the thermal contours and the influence of centre to centre spacings of web openings for, (a) $150 \mathrm{~mm}$ centres; (b) $200 \mathrm{~mm}$ centres; (c) $300 \mathrm{~mm}$ centres; (d) $600 \mathrm{~mm}$ centres

During the experimental investigation it was found that a major temperature difference exists on the steel web at openings and on the adjacent solid part while the other parts of the beam, including the bottom flange, the welded steel plate and the top flange were not highly affected. To analyse the influence of the opening spacings, respective temperature differences predicted during the analysis for the thermocouple positions 3 and 5 (shown earlier in Figure 1) at section $\mathrm{AA}^{\prime}$ and $\mathrm{BB}^{\prime}$ are presented in Figure 9 (a) and Figure 9 (b) respectively. It is seen that for smaller centre to centre spacing of openings, temperature differences between the web below the opening and on the adjacent solid steel web are smaller compared to those predicted for larger opening spacings. Similarly, temperatures differences predicted on the steel web above the web openings and on the adjacent solid steel web at thermocouple position 5 are lesser for smaller opening spacings compared to those predicted for larger opening spacings. Nevertheless, in all cases, temperatures recorded on the web below the openings are higher in comparison to those predicted on the adjacent solid steel web. The predicted temperatures are lesser on the steel web above the opening in comparison to those predicted on the adjacent solid steel web. 


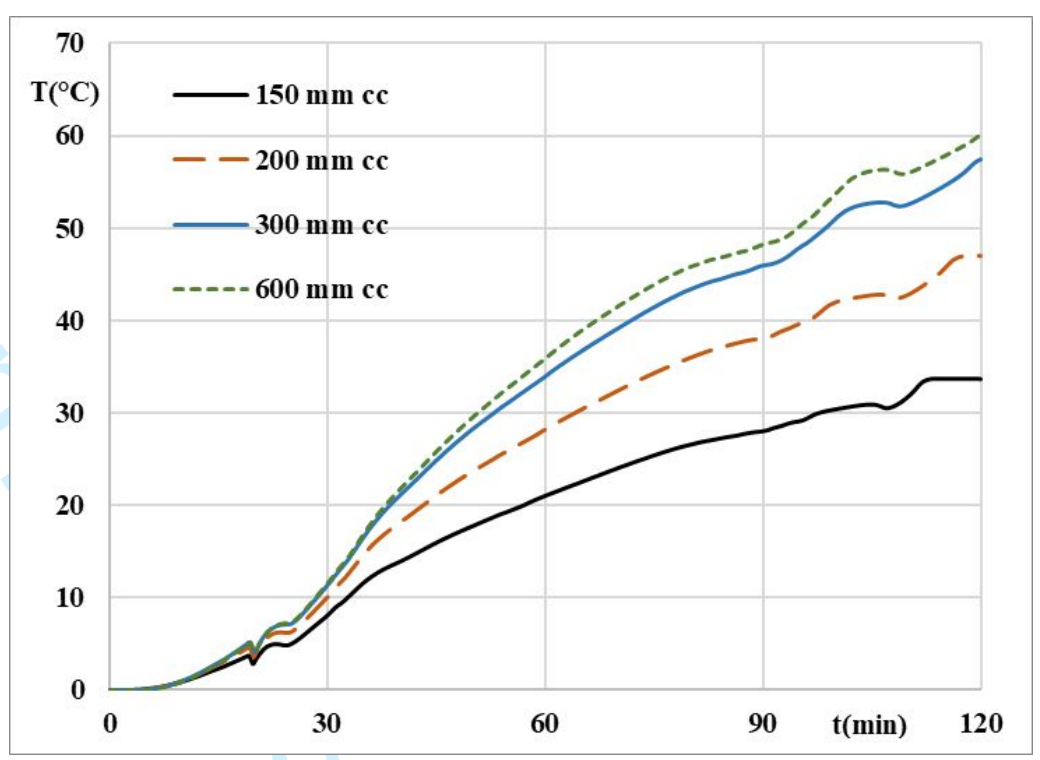

(a)

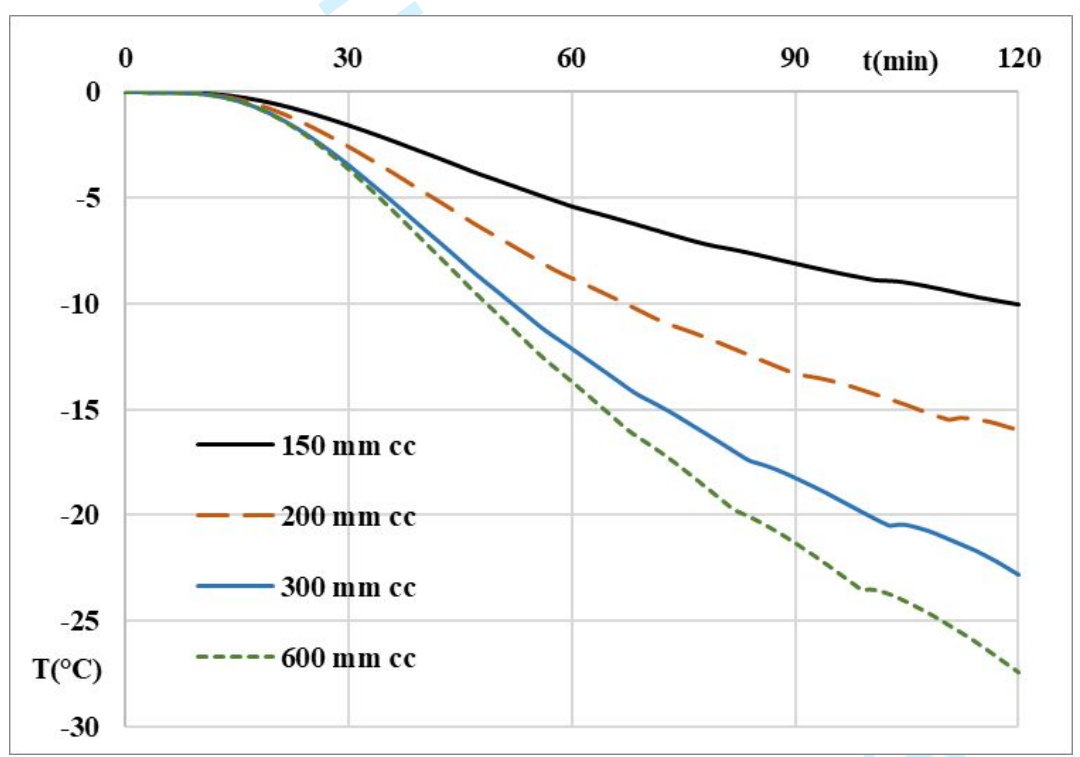

(b)

Figure 9: Temperatures differences on the steel web at openings and on the adjacent solid steel web for different spacings of web openings, (a) for thermocouple positions 3; (b) for thermocouple positions 5

Temperatures predicted at the thermocouple position 3 below the web openings for all cases were found be similar irrespective of the centre to centre spacings of the openings. However, a difference in the predicted temperatures on the solid steel web was observed at the same thermocouple positions, the thermocouple position 3. The thermal predictions at thermocouple position 3 on the solid web for all cases are presented in Figure 10. It is seen that the predicted temperatures are higher for the case with lesser centre to centre spacings of the openings and vice versa. This is due to the width of the solid steel web which is smaller for closely spaced openings and larger for widely spaced openings. The predicted temperatures are higher for smaller widths of the solid steel web and lower for larger steel web widths. These results show that for smaller opening spacings, the temperatures under the web openings as well as those on the adjacent solid steel web are higher in comparison to the case 
where the spacing of the web openings are larger. Hence, for slim floor beam with closely spaced web openings, higher temperatures are produced on the steel web under the openings as well as on the adjacent steel web which presents a more severe case. In case where the spacings of the openings are larger, temperatures under the web are higher but the temperatures predicted for the solid steel web are lower resulting in a less severe case.

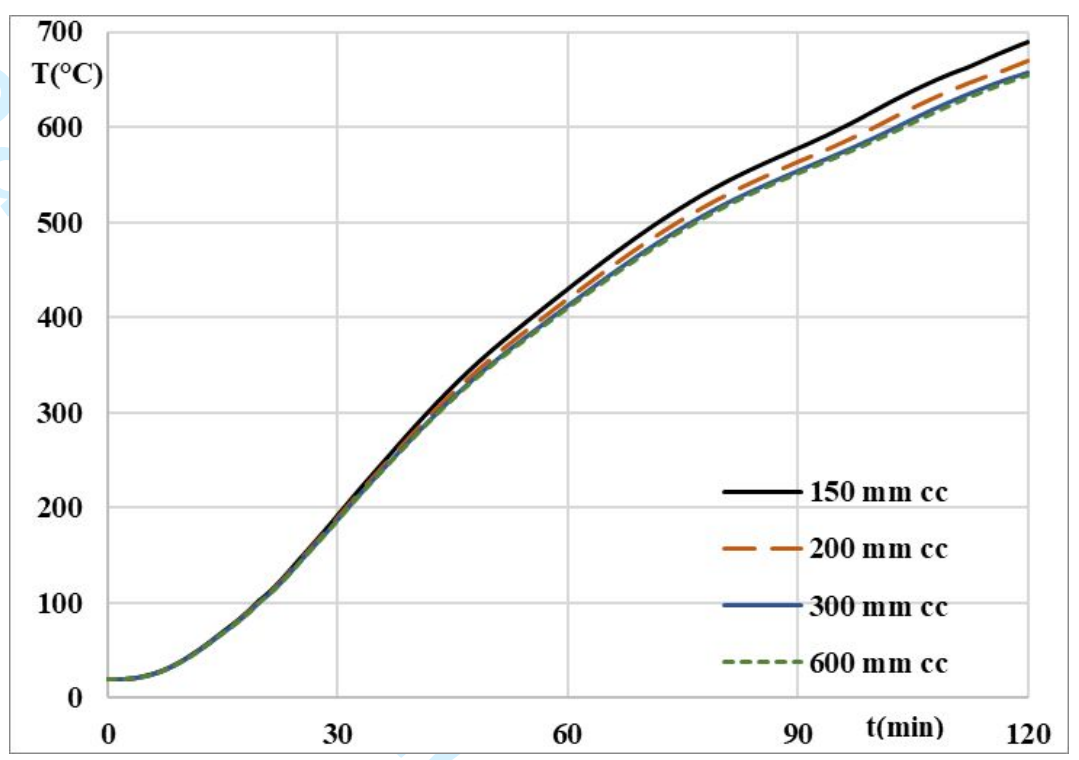

Figure 10: Predicted temperatures at the thermocouple position 3 on the solid steel web for different centre to centre spacings of web openings

\subsection{Sensitivity studies on the size of openings}

During this part of the sensitivity study, the size of the openings was different in each investigated case while the openings were positioned along the centreline of the steel web as before. Further, these openings were positioned in such a way that the minimum width of the solid web between the openings was $100 \mathrm{~mm}$, same in all cases. Due to the variations in the size of the openings, depth of the solid web above and below the openings was different in each case. For the case with $50 \mathrm{~mm}$ size openings, the depth of the steel web above and below the opening was $69 \mathrm{~mm}$ while for the case with $70 \mathrm{~mm}$ openings, this was $59 \mathrm{~mm}$. In case of the slim floor beam with $100 \mathrm{~mm}$ web openings, the size of steel web above and below the opening was $44 \mathrm{~mm}$ while for the case with $130 \mathrm{~mm}$ size web openings, this depth was only $29 \mathrm{~mm}$. The thermal results from the analysis after 120 minutes of standard fire exposure are presented in Figure 11. The thermal contours in Figure 11 show that the temperatures on the parts of the steel web above and below the openings are influenced due to the variations in the size web openings. On the other hand, the temperatures predicted on the solid steel web between the openings are less influenced by their similar widths. 
Temperature variations on the steel web are presented in terms of the temperature differences at the openings and on the solid steel web respectively for thermocouple positions 3 and 5 in Figure 12 (a) and Figure 12 (b) respectively. These temperature differences presented are the ones predicted on the steel web above and below the openings and at the adjacent solid steel web and at similar thermocouple positions. The temperature differences on the lower parts of the steel web are highest for the largest opening size, the case with $130 \mathrm{~mm}$ diameter openings. On the other hand, these differences are minimum for the case where the size of the web openings is the smallest as shown in Figure 12 (a). The temperatures predicted below the web openings are higher compared to those predicted for the adjacent solid steel web in all cases. On the other hand, the temperatures predicted on the solid steel web are higher compared to those predicted on the steel web above the opening at thermocouple position 5 as shown in Figure 12 (b). Similar to the bottom part of the web, the difference in the predicted temperatures are higher for larger opening sizes compared to smaller sizes. These results show that severe temperature distributions are produced in slim floor beams with larger web opening sizes in comparison with the beams with smaller web opening sizes.

(b)

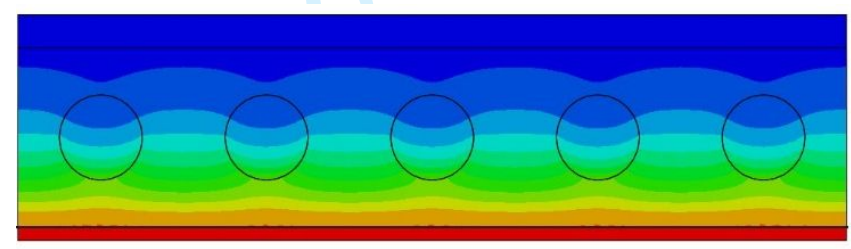

(c)

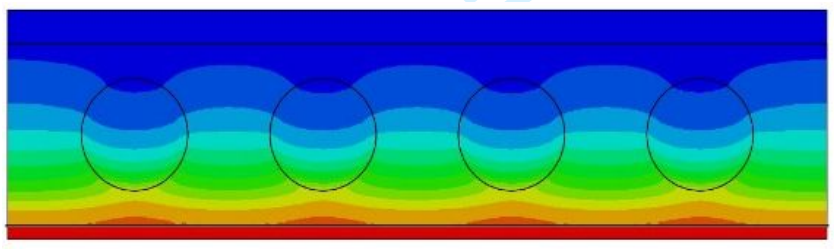

(d)

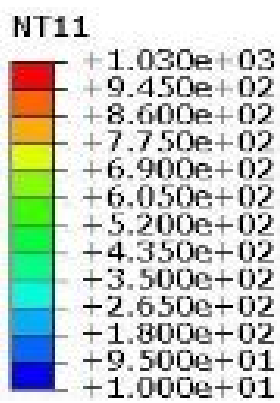

Figure 11: Thermal contours and analytical results on the influence of the size of web openings, (a) $50 \mathrm{~mm}$ diameter openings; (b) $70 \mathrm{~mm}$ diameter openings; (c) $100 \mathrm{~mm}$ diameter openings; (d) $130 \mathrm{~mm}$ diameter openings 
Figure 12: Temperatures differences on the steel web at openings and on the adjacent solid steel web for different opening sizes, (a) for thermocouple positions 3; (b) for thermocouple positions 5

Due to the change in the size of the web openings, the depth of the steel web above and below the opening was different for each slim floor beam assembly. To analyse the influence of the varying depth of the steel web, the predicted temperatures on the lower part of the steel web, at $20 \mathrm{~mm}$ from the inner side of the bottom flange, are presented in Figure 13. It can be seen that the predicted temperatures on the bottom part of the steel web under the openings are higher for larger sizes of the web openings compared to those for smaller sizes. Hence, larger web openings produce more severe temperature distributions compared to the smaller web openings in slim floor beams exposed to fire. 
Figure 13: Predicted temperatures at thermocouple position 3 on steel web under the openings for slim floor beams with different opening sizes

\subsection{Sensitivity studies on the shape of openings}

The sensitivity study on the opening shapes consists of four cases. The first case consisted of a slim floor beam with $100 \mathrm{~mm}$ diameter circular web openings while the second case consisted of $100 \mathrm{~mm}$ square shaped web openings. Keeping in view the opening shapes currently used for cellular composite beams, slim floor beams with elongated and rectangular web openings were also investigated. These shapes were included in the analysis anticipating their possible future use in slim floor constructions. The elongated openings were $100 \mathrm{~mm}$ deep and $300 \mathrm{~mm}$ long with semi circles of $100 \mathrm{~mm}$ diameter at each end. The rectangular web openings investigated were $100 \mathrm{~mm}$ deep and 300 $\mathrm{mm}$ long. All these openings were aligned with the geometric centre of the steel web which resulted in $44 \mathrm{~mm}$ depth of the steel web above and below the openings. Further, in all cases the minimum width of the solid steel web was kept similar and was $100 \mathrm{~mm}$ between the edges of the openings. Results from the analysis obtained after 120 minutes of standard fire exposure are presented in Figure 14. It can be seen that the shape of the web openings has an influence on the thermal response of these beams when exposed to standard fire. These temperature variations are easily visible from the thermal contours shown in Figure 14 for all slim floor beam cases. Due to the variations in the shape of the openings, the length of the solid steel web below the openings is different for all cases. For the circular openings, this length is just a point and changes along its length. For the square openings, the length of the web below the opening is $100 \mathrm{~mm}$ while for the rectangular openings, this length is 300 $\mathrm{mm}$. In case of elongated openings, the length of the steel web below the openings is $200 \mathrm{~mm}$ as shown previously in Figure 7. 


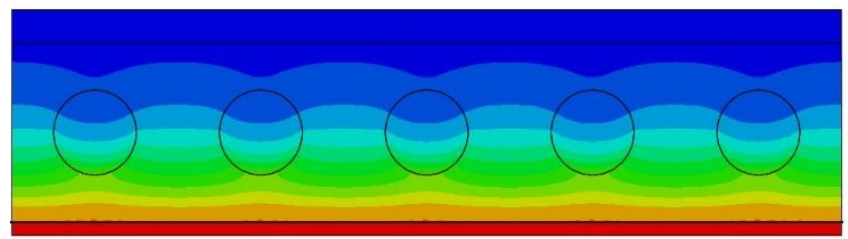

(a)

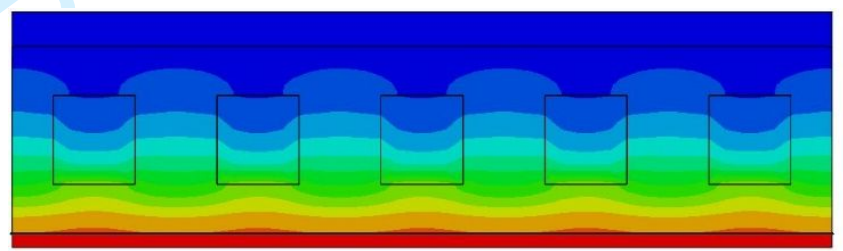

(b)

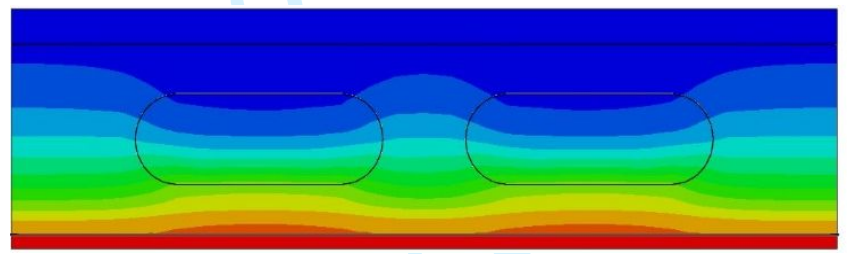

(c)

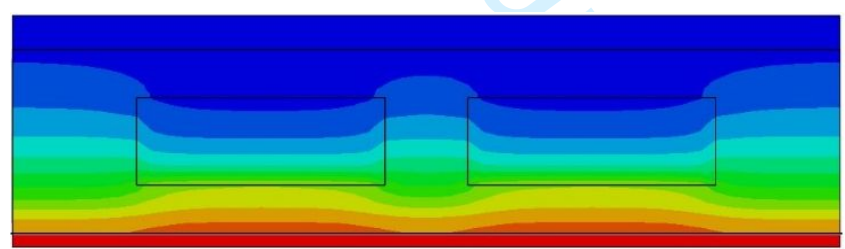

(d)

Figure 14: Thermal contours and analytical results on the influence of opening shapes, (a) 100 mm diameter circular openings; (b) $100 \mathrm{~mm}$ square openings; (c) $300 \mathrm{~mm}$ elongated openings; (d) $300 \mathrm{~mm}$ rectangular openings

The results from the analytical investigation are presented in terms of the temperature differences on the web at the centreline of the openings and those on the adjacent solid steel web in Figure 15. The results presented in Figure 15 (a) and Figure 15 (b) are the respective temperature differences at section AA and section BB for thermocouple positions 3 and 5. It can be seen in Figure 15 (a) that the temperature differences on the bottom parts of the steel web are the lowest for the circular openings as comparted to other investigated opening shapes. These differences are still low for the square shaped openings in comparison to the elongated and the rectangular web openings. The differences in temperatures for the rectangular openings were found to be the highest as shown in Figure 15 (a). Similar pattern of thermal differences was observed on the upper parts of the steel web where the temperatures on the solid part of the steel web were higher compared to those predicted on the adjacent steel web above the openings, thermocouple position 5 . These differences were highest for rectangular openings and lowest for circular openings as shown in Figure 15 (b). 


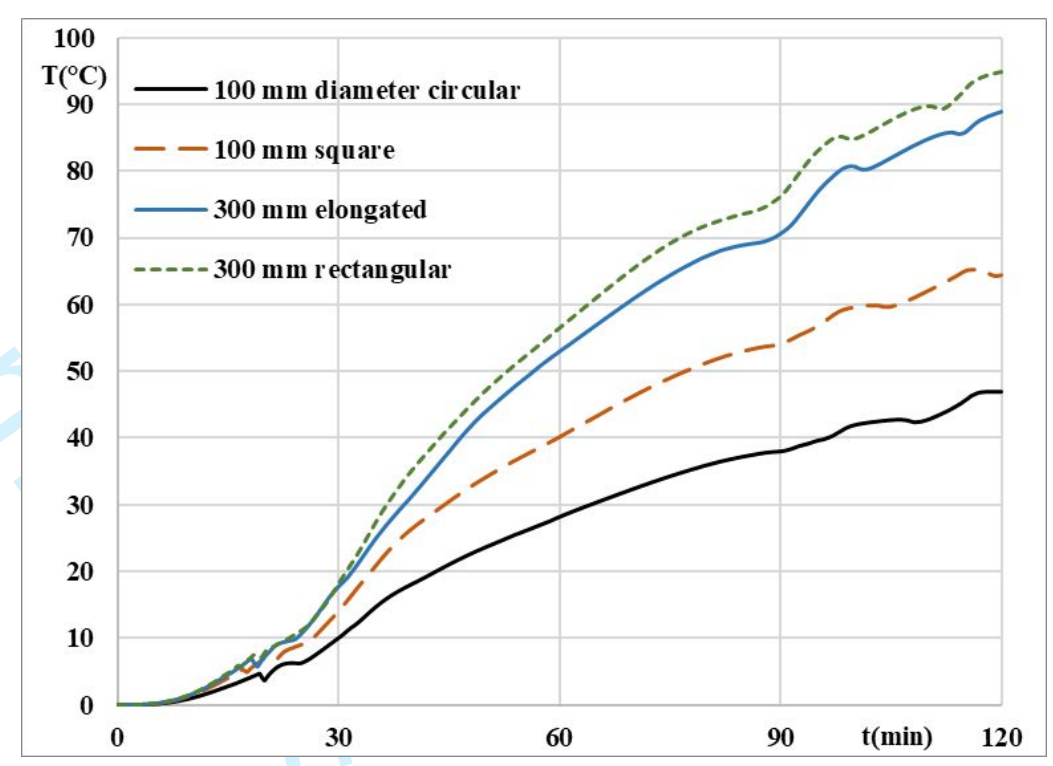

(a)

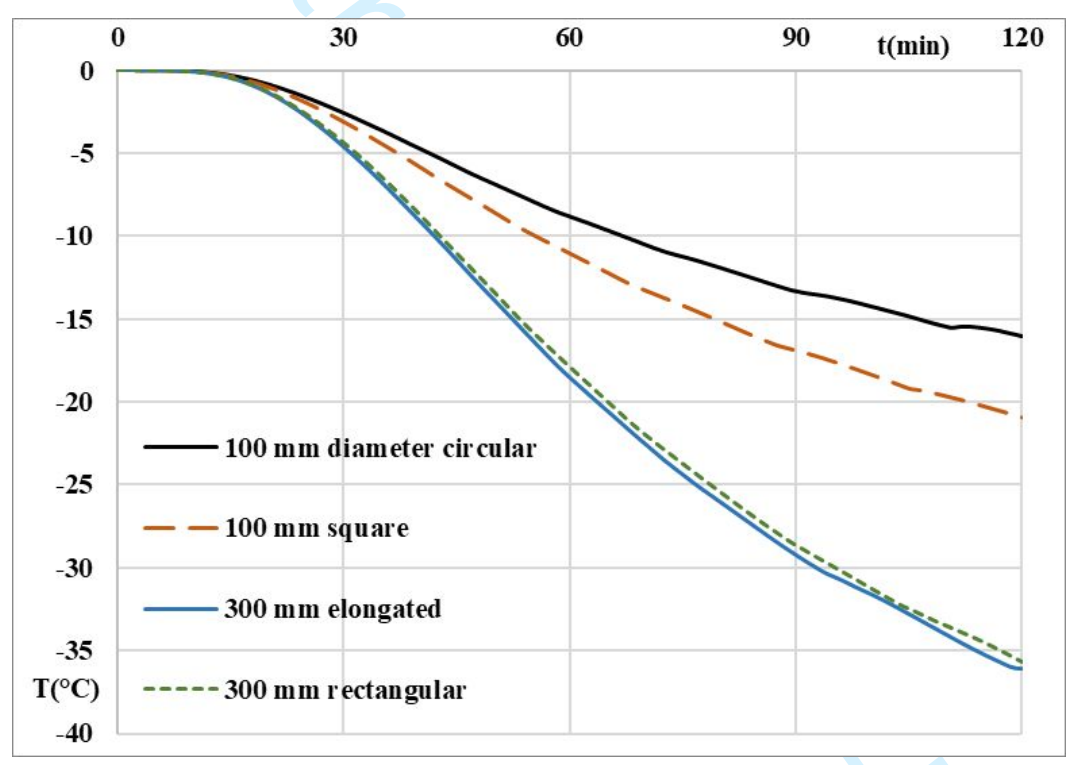

(b)

Figure 15: Temperatures differences on the steel web at openings and on the adjacent solid steel web for different shapes of web openings, (a) for thermocouple positions 3; (b) for thermocouple positions 5

To analyse the influence of the variations in the length of the steel web below the openings resulting from different opening shapes, temperatures predicted at the centreline of the openings at thermocouple position 3 below the openings at section BB' $^{\prime}$ are presented in Figure 16. The predicted temperatures at thermocouple position 3 are the lowest for the circular web openings. These predicted temperatures on the same parts of web are higher for square shaped openings compared to circular openings and are lesser in comparison with those predicted for elongated and rectangular shaped openings. The predicted temperatures in case of the rectangular openings were found to be the highest while those predicted for the elongated openings were very close to the ones predicted for rectangular openings. These results show that the temperature distributions for slim floor beams with rectangular and elongated web openings are the most severe while for those with circular web openings these are the least severe. 


\section{Conclusions}

This research presents the findings from an experimental and an analytical investigation conducted to study the influence of the web openings on thermal behaviour of slim floor beams in fire. Some conclusions from the research are listed below;

- During the experimental investigation, it was found that the presence of web openings has a considerable influence on the thermal behaviour of slim floor beams in fire. It was observed that the presence of the web openings induces higher temperatures on the parts of web below the openings compared to those on the adjacent solid steel web.

- The behaviour of the slim floor beam from the fire test was replicated using finite element modelling with the purpose to conduct a sensitivity study.

- During the sensitivity study, it was observed that smaller centre to centre spacing of openings develops more severe temperature distributions compared to larger spacing of openings. The closer arrangement of the web openings produces higher temperatures on the steel web below the openings as well as on the adjacent solid steel web. This is the result of the reduced size of the solid steel web width in case of closely spaced openings.

- Investigations on the influence of the opening sizes show that the temperature differences on the bottom part of the steel web, under the openings and on the adjacent solid steel web, are more severe for larger opening sizes compared to those for smaller openings. This is due to the reduction in depth of the steel web under the opening resulting from an increase in their size.

- The investigation on shapes of the openings shows that the presence of the circular web openings produces less severe temperature distributions compared to square, elongated and rectangular web openings. The rectangular web openings were found to produce the most severe temperature distributions on the slim floor beams. Hence, opening spacings, sizes and shapes were found to have an influence on the thermal response of slim floor beams in fire. 
- The results from this study show that the presence of web openings has a considerable influence on the thermal behaviour of slim floor beams in fire. Closely spaced, large and rectangular openings have a more severe influence on their thermal behaviour compared to widely spaced, small and circular web openings. Such interventions and design fabrications in slim floor beams required due attention in relation to their fire response. In cases where designs with web openings are required, the shape of the openings should be kept small and circular and should be fabricated at larger centre to centre spacings.

The current investigation addresses only the thermal behaviour of slim floor beams with web openings in fire. It is early to conclude the influence of these openings on mechanical response of slim floor beams in fire at this stage. Slim floor beams designs are still evolving, and further experimental and analytical investigations are required to analyse any influence of web openings on mechanical response of slim floor beams exposed to fire.

\section{REFERENCES}

1. De Nardin, S. \& El Debs, A.L.H.C., 2009. Study of partially encased composite beams with innovative position of stud bolts. Journal of Constructional Steel Research, 65(2), pp.342350.

http://dx.doi.org/10.1016/j.jcsr.2008.03.021.

2. D. L. Mullet, (1998), Composite Floor Systems, The Steel Construction Institute, 1st edition London.

3. Newman, G.M., (1995), Fire resistance of slim floor beams. Journal of Constructional Steel Research, 33(1-2), pp.87-100. http://dx.doi.org/10.1016/0143-974x(94)00016-b.

4. Tsavdaridis, K.D., D'Mello, C. \& Huo, B.Y., 2013. Experimental and computational study of the vertical shear behaviour of partially encased perforated steel beams. Engineering Structures, 56, pp.805-822. http://dx.doi.org/10.1016/j.engstruct.2013.04.025.

5. Tsavdaridis, K.D. \& D'Mello, C., 2012. Vierendeel Bending Study of Perforated Steel Beams with Various Novel Web Opening Shapes through Nonlinear Finite-Element Analyses. Journal of Structural Engineering, 138(10), pp.1214-1230. http://dx.doi.org/10.1061/(asce)st.1943-541x.0000562.

6. Huo, B.Y. \& D'Mello, C.A., 2013. Push-out tests and analytical study of shear transfer mechanisms in composite shallow cellular floor beams. Journal of Constructional Steel Research, 88, pp.191-205.

http://dx.doi.org/10.1016/j.jcsr.2013.05.007

7. International Standards Organization. (1999). ISO 834-1, Fire Resistance Tests- Elements of Building Construction. Part 1: General Requirements. International Standards Organization.

8. Alam, N., Nadjai, A., Ali, F., Nadjai, W., (2018). Structural response of unprotected and protected slim floors in fire. Journal of Constructional Steel Research, 142, pp.44-54. http://dx.doi.org/10.1016/j.jcsr.2017.12.009.

9. Maraveas, C., Tsavdaridis, K.D., Nadjai, A., (2016). Fire Resistance of Unprotected Ultra Shallow Floor Beams (USFB): A Numerical Investigation, Fire Technology 53 (2): 609-627. https://doi.org/10.1007/s10694-016-0583-5

10. Alam, N., Nadjai, A., Maraveas, C., Tsavdaridis, K.D., (2018) Response of Asymmetric Slim Floor Beams in Parametric Fires. Journal of Physics: Conference Series. European Symposium on Fire Safety Science (ESFSS 2018), 12-14 Sep 2018, Nancy, France. 
11. Alam, N., Nadjai, A., Maraveas, C., Tsavdaridis, K.D., Kahanji, C. (2018) Effect of Air-gap on Response of Fabricated Slim Floor Beams in Fire, Journal of Structural Fire Engineering https://doi.org/10.1108/JSFE-04-2018-0011

12. ABAQUS, (2016), Finite Element Modelling Programme and Standard User's Manual, Version 6.14. SIMULIA.

13. Maraveas, C., Swailes, T. \& Wang, Y., (2012), A detailed methodology for the finite element analysis of asymmetric slim floor beams in fire. Steel Construction, 5(3), pp.191-198.

14. European Committee for Standardization, (2014), BS EN 1994-1-2: Eurocode 4: Design of composite steel and concrete structures - General rules - Structural fire design, European Committee for Standardization, Vol. 3.

15. European Committee for Standardization, (2008), BS EN 1992-1-2 Eurocode 2: Design of concrete structures part 1-2 General rules - Structural fire design, European Committee for Standardization.

16. European Committee for Standardization (2009), BS EN 1993-1-2 Eurocode 3: Design of steel structures, Part 1-2, General rules - Structural fire design, European Committee for Standardization.

17. European Committee for Standardization (2009), EN1991-1-2, Eurocode 1 - Actions on structures - Part 1-2: General Rules -Structural Fire Design, European Committee for Standardization.

18. British Standards Institution. (1987). BS 476 Part-20:1987. (2012). Fire tests on building materials and structures. Method for determination of the fire resistance of elements of construction (general principles). 